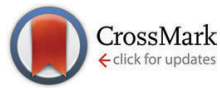

Cite this: Phys. Chem. Chem. Phys., $2015,17,10238$

Received 12th February 2015, Accepted 12th March 2015

DOI: $10.1039 / \mathrm{c} 5 \mathrm{cp} 00870 \mathrm{k}$

www.rsc.org/pccp

\section{4-Hydroxy-1-naphthaldehydes: proton transfer or deprotonation $\dagger$}

\author{
Y. Manolova, ${ }^{a}$ V. Kurteva, ${ }^{a}$ L. Antonov, ${ }^{\star a}{ }^{a}$ H. Marciniak, ${ }^{b}$ S. Lochbrunner, ${ }^{b}$ \\ A. Crochet, ${ }^{c}$ K. M. Fromm, ${ }^{c}$ F. S. Kamounah ${ }^{d}$ and P. E. Hansen ${ }^{d}$
}

A series of naphthaldehydes, including a Mannich base, have been investigated by UV-Vis spectroscopy, NMR and theoretical methods to explore their potential tautomerism. In the case of 4-hydroxy-1naphthaldehyde concentration dependent deprotonation has been detected in methanol and acetonitrile. For 4-hydroxy-3-(piperidin-1-ylmethyl)-1-naphthaldehyde (a Mannich base) an intramolecular proton transfer involving the $\mathrm{OH}$ group and the piperidine nitrogen occurs. In acetonitrile the equilibrium is predominantly at the $\mathrm{OH}$-form, whereas in methanol the proton transferred tautomer is the preferred form. In chloroform and toluene, the $\mathrm{OH}$ form is completely dominant. Both 4-hydroxy-1-naphthaldehyde and 4-methoxy-1-naphthaldehyde (fixed enol form) show dimerization in the investigated solvents and the crystallographic data, obtained for the latter, confirm the existence of a cyclic dimer.

\section{Introduction}

The concept of molecular electronics, ${ }^{1-3}$ based on the use of single molecules as building elements (wires, switches, rectifiers, etc.) and their further suitable assembly into working devices, has catalyzed intensive investigations in order to find such molecular level "hardware". The main emphasis is on organic and hybrid systems, because a wide range of molecular propensities can be combined with the versatility of synthetic chemistry to alter and optimize molecular structures in the direction of desired properties.

Virtually, every single molecule changes its behavior when acted upon by external stimuli, but its use as a molecular switch is possible only if these changes are reproducible, reversible and can be controlled and monitored. ${ }^{4}$ Among the variety of types $^{5}$ of switching systems, several systems based on tautomeric proton exchange have recently been reported. ${ }^{6-8}$ It is not surprising that tautomerism has attracted attention in this field - the main requirement in the design of molecular switches is to provide fast and clean interconversion between

\footnotetext{
${ }^{a}$ Institute of Organic Chemistry with Centre of Phytochemistry, Bulgarian Academy of Sciences, Acad. G.Bonchev str., bldg. 9, Sofia 1113, Bulgaria. Web: http://www.orgchm.bas.bg/ i2mp

${ }^{b}$ Institut für Physik, Universität Rostock, Universitätsplatz 3, 18051 Rostock, Germany

${ }^{c}$ Department of Chemistry, University of Fribourg, Chemin du Musée 9, 1700 Fribourg, Switzerland

${ }^{d}$ Department of Science, Systems and Models, Roskilde University, Universitetsvej 1, P.O.Box 260, DK-4000 Roskilde, Denmark

$\dagger$ Electronic supplementary information (ESI) available. CCDC 1043758. For ESI and crystallographic data in CIF or other electronic format see DOI: 10.1039/ c5cp00870k
}

structurally different molecular (on- and off-) states and tautomerism is an excellent possibility, because the change in the tautomeric state is accomplished by a fast proton transfer reaction between two or more structures, each of them with clearly defined and different molecular properties. The main problem ${ }^{9}$ is to provide conditions for a controlled shift of the tautomeric equilibrium in a way that the on- and off-states correspond to the individual tautomers.

The conceptual idea of a keto-enol tautomeric switch, developed recently by us, is presented in Fig. $1 .^{7,10,11}$ On one side, the enollike off-state is achieved by engagement of the tautomeric proton in an intramolecular hydrogen bond with a macrocyclic antenna, connected to the tautomeric unit by a spacer. On the other side,

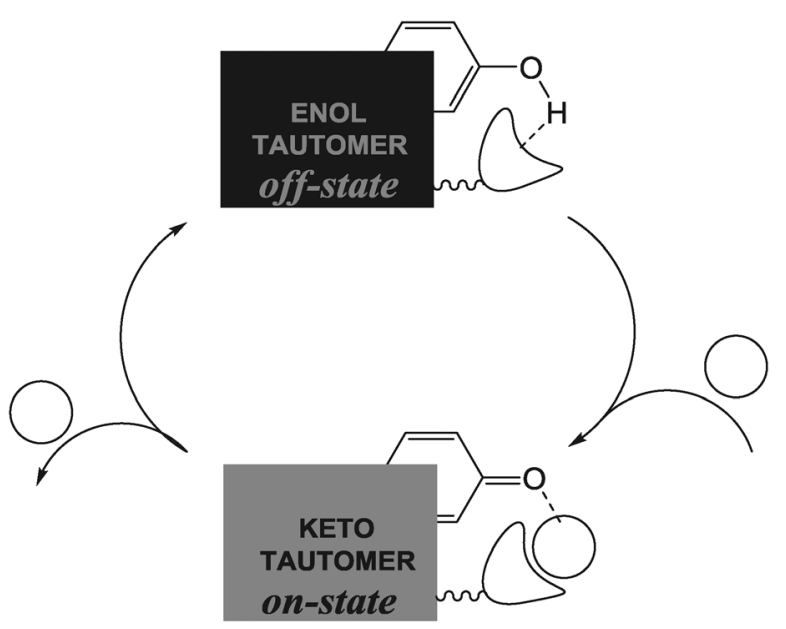

Fig. 1 Control of switching in a keto-enol tautomeric system. 


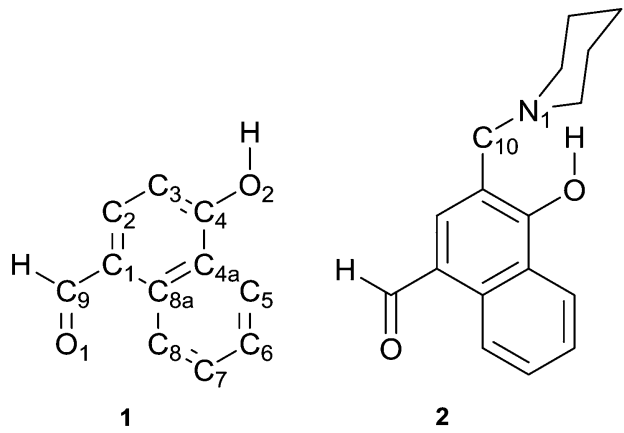<smiles>COc1ccc(C=O)c2ccccc12</smiles>

3<smiles>CC(C)C(=O)c1ccc(O)c2ccccc12</smiles>

4

Scheme 1 Compounds under investigation with numbering of the heavy atoms.

the engagement of the same antenna with external stimuli (like the addition of an $\operatorname{acid}^{7}$ or metal ions ${ }^{10}$ ) causes a change in the tautomeric state, switching to the keto-like on-state.

The real switching needs a moderate energy gap between the individual (i.e. without attached antenna) tautomeric building blocks, because the stabilizing effect of the neutral antenna on the enol form and the stabilizing effect of the protonated antenna on the keto form vary depending on the tautomeric compound. For instance, the switching in solution with a piperidine antenna is possible in azonaphthols and related Schiff bases, where the relative energy between individual tautomers is $\sim 1.5 \mathrm{kcal} \mathrm{mol}^{-1}$ and $\sim 4 \mathrm{kcal} \mathrm{mol}^{-1}$ (the enol form more stable) respectively, but impossible in azophenols where the energy gap is more than $10 \mathrm{kcal} \mathrm{mol}^{-1}$.,11 $^{7}$ In addition the size of these systems does not allow detailed theoretical studies using sophisticated DFT functionals with large basis sets.

For this reason, in this paper we devote our efforts to the possibilities of switching in 4-hydroxy-1-naphthaldehyde (1, Scheme 1) and its analogue with an attached piperidine antenna (2). Compound $\mathbf{1}$ is potentially tautomeric, but from its structure it is clear that switching from the enol to keto form could lead to destabilization due to the loss of aromaticity of the naphthalene ring. Therefore it represents a suitable example to model processes of switching in systems with a large energy gap between individual tautomers. To the best of our knowledge no detailed theoretical and experimental investigations of the spectral behavior of these two compounds have been carried out to date, taking into account that the general template for the synthesis of compound 2 was recently reported for the first time. ${ }^{12}$ In addition, the interpretation of the results is supported by the study of compounds 3 and $\mathbf{4}$, which model different aspects of the behavior of $\mathbf{1}$ in solution.

\section{Experimental part}

\section{General}

All reagents were purchased from Merck, Aldrich and Fluka and were used without any further purification. Fluka silica gel/TLCcards 60778 with a fluorescent indicator at $254 \mathrm{~nm}$ were used for TLC chromatography. The melting points were determined in capillary tubes on a SRS MPA100 OptiMelt (Sunnyvale, CA, USA) automated melting point system. The NMR spectra were recorded on a Bruker Avance II+ 600 spectrometer at $25{ }^{\circ} \mathrm{C}$ or on a Varian Mercury 300 system; the chemical shifts were quoted in ppm in $\delta$-values against tetramethylsilane (TMS) as an internal standard and the coupling constants were calculated in $\mathrm{Hz}$. The assignment of the signals was confirmed by applying $2 \mathrm{D}$ techniques. The spectra were recorded for $3 \times 10^{-2} \mathrm{M}$ solutions in order to avoid transmolecular interactions in the NOESY experiments. The spectra were processed using the Topspin 2.1 program.

Compound 1 was purchased from Aldrich (No. 131067).

Compound 2 (4-hydroxy-3-(piperidin-1-ylmethyl)-1-naphthaldehyde ${ }^{12}$ ) was synthesized according to the following procedure: to a solution of piperidine $(2.2 \mathrm{mmol})$ in benzene $(15 \mathrm{ml})$ paraformaldehyde $(2.2 \mathrm{mmol}), p$-toluenesulfonic acid $(15 \mathrm{mg})$, and then 4-hydroxy-1-naphthaldehyde $(2 \mathrm{mmol})$ were added and the mixture was refluxed with stirring for $3 \mathrm{~h}$. The products were partitioned between benzene and water. The organic phase was dried over $\mathrm{Na}_{2} \mathrm{SO}_{4}$, evaporated to dryness, and purified by HPFC or flash chromatography on a silica gel by using a mobile phase with a gradient of polarity from $\mathrm{CH}_{2} \mathrm{Cl}_{2}$ to acetone- $\mathrm{CH}_{2} \mathrm{Cl}_{2} 1: 9$ to obtain pure 2: $85 \%$ yield; $R_{\mathrm{f}} 0.34$ (acetone- $\mathrm{CH}_{2} \mathrm{Cl}_{2} 1$ : 9 ); light yellowish solid, m.p. 106.7-106.9 ${ }^{\circ} \mathrm{C} ;{ }^{1} \mathrm{H}$ NMR $\left(\mathrm{CDCl}_{3}, 600 \mathrm{MHz}\right)$ 1.382 (bs, $2 \mathrm{H}, \mathrm{CH}_{2}-4$ piperidine), 1.739 (bs, $4 \mathrm{H}, \mathrm{CH}_{2}-3$ and $\mathrm{CH}_{2}-5$ piperidine), 2.248 (bs, $2 \mathrm{H}, 1 / 2$ of $\mathrm{CH}_{2}-2$ and $\mathrm{CH}_{2}-6$ piperidine), 3.100 (bs, $2 \mathrm{H}, 1 / 2$ of $\mathrm{CH}_{2}-2$ and $\mathrm{CH}_{2}-6$ piperidine), $3.930(\mathrm{~s}, 2 \mathrm{H}$, Ar- $\mathrm{CH}_{2}-\mathrm{N}$ ), 7.565 (ddd, $1 \mathrm{H}, J 1.2,6.8,8.2, \mathrm{CH}-6 \mathrm{Ar}$ ), 7.607 (s, $1 \mathrm{H}$, $\mathrm{CH}-2 \mathrm{Ar}$ ), 7.681 (ddd, $1 \mathrm{H}, J 1.4,6.8,8.3, \mathrm{CH}-7 \mathrm{Ar}$ ), 8.350 (ddd, $1 \mathrm{H}$, $J$ 0.7,1.4, 8.4, $\mathrm{CH}-5 \mathrm{Ar}$ ), 9.257 (ddd, $1 \mathrm{H}, J 0.8,1.0,8.5, \mathrm{CH}-8 \mathrm{Ar}$ ), $10.167(\mathrm{~s}, 1 \mathrm{H}, \mathrm{C} H=\mathrm{O}), 10.639$ (bs, $1 \mathrm{H}, \mathrm{OH}) ;{ }^{13} \mathrm{C}$ NMR 23.73 $\left(\mathrm{CH}_{2}-4\right.$ piperidine), $25.64\left(\mathrm{CH}_{2}-3\right.$ and $\mathrm{CH}_{2}-5$ piperidine), 53.77 $\left(\mathrm{CH}_{2}-2\right.$ and $\mathrm{CH}_{2}-6$ piperidine), $61.66\left(\mathrm{Ar}-\mathrm{CH}_{2}-\mathrm{N}\right), 112.67\left(\mathrm{C}_{\text {quat }}-3\right)$, $122.47\left(C_{\text {quat }}-1\right), 122.69(\mathrm{CH}-5 \mathrm{Ar}), 124.49(\mathrm{CH}-8 \mathrm{Ar}), 125.18$ ( $\left.C_{\text {quat }}-4 \mathrm{a}\right), 125.82(\mathrm{CH}-6 \mathrm{Ar}), 129.32(\mathrm{CH}-7 \mathrm{Ar}), 131.92$ ( $\left.C_{\text {quat }}-8 \mathrm{a}\right)$, $138.95(\mathrm{CH}-2 \mathrm{Ar}), 162.20\left(C_{\text {quat }}{ }^{4}\right), 191.56(\mathrm{CH}=\mathrm{O})$; COSY cross peaks 7.565/7.607, 7.565/8.350, 7.607/9.257; NOESY cross peaks 1.382/1.739, 1.739/2.248 (weak), 1.739/3.100 (weak), 2.248/3.100, 2.248/3.930 (weak), 3.100/3.930 (weak), 3.930/7.607, 7.565/7.681, 7.565/8.350, 7.607/10.167, 7.681/9.257, 9.257/10.167; HSQC cross peaks 1.382/23.73, 1.739/25.64, 2.248/53.77, 3.100/53.77, 3.930/ 61.66, 7.565/125.82, 7.607/138.95, 7.681/129.32, 8.350/122.69, 9.257/124.49, 10.167/191.56; HMBC cross peaks 1.739/23.73 (weak), 3.930/53.77, 3.930/112.67, 3.930/138.95, 3.930/162.20, $7.565 / 124.49,7.565 / 125.18,7.607 / 61.66,7.607 / 131.92,7.607 /$ 162.20, 7.607/191.56, 7.681/122.69, 7.681/131.92, 8.350/129.32, 
8.350/131.92, 8.350/162.20, 9.257/122.47, 9.257/125.18, 9.257/ 162.20 (weak), 10.167/122.47, 10.167/131.92, 10.167/138.95.

Compound 3 (4-methoxy-1-naphthaldehyde ${ }^{13}$ ) was synthesized as follows: a mixture of 1-hydroxy-4-naphthaldehyde (1 mmol), $\mathrm{NaOH}(2 \mathrm{mmol})$ and $\mathrm{CH}_{3} \mathrm{I}(10 \mathrm{mmol})$ in dry THF $(20 \mathrm{ml})$ was stirred at room temperature for $6 \mathrm{~h}$. The solvent was removed in vacuo and the products were purified by HPFC on a silica gel using a mobile phase with a gradient of polarity from DCM to $1 \%$ acetone/DCM to give pure 3: $98 \%$ yield; $R_{\mathrm{f}} 0.62$ (1\% acetone/DCM); m.p. $34.2-34.6{ }^{\circ} \mathrm{C}$ (lit. $\left.{ }^{13} 34{ }^{\circ} \mathrm{C}\right) ;{ }^{1} \mathrm{H}$ NMR $\left(\mathrm{CDCl}_{3}, 600 \mathrm{MHz}\right) 4.077$ (s, 3H, OCH $), 6.893$ (d, 1H, J 8.1, CH-3), 7.559 (ddd, $1 \mathrm{H}, J$ 1.3, 6.9, 8.3, CH-6), 7.687 (ddd, 1H, J 1.4, 6.9, 8.4, CH-7), 7.896 (d, 1H, J 8.1, CH-2), 8.318 (ddd, 1H, $J$ 0.7,1.3, 8.4, CH-5), 9.297 (ddd, $1 \mathrm{H}, J$ 0.7, 1.1, 8.6, CH-8), 10.191 (s, $1 \mathrm{H}$, $\mathrm{CH}=\mathrm{O}) ;{ }^{13} \mathrm{C}$ NMR $55.98\left(\mathrm{OCH}_{3}\right), 102.92(\mathrm{CH}-3), 122.38(\mathrm{CH}-5$ $\mathrm{Ar}), 124.87$ (CH-8), $125.02\left(C_{\text {quat }}-1\right), 125.53\left(C_{\text {quat }}-4 \mathrm{a}\right), 126.40$ (CH-6), 129.53 (CH-7), 131.90 ( $\left.C_{\text {quat }}{ }^{-8 a}\right), 139.64$ ( $\left.C H-2\right), 160.85$ $\left(C_{\text {quat }}{ }^{-4}\right), 192.27(\mathrm{CH}=\mathrm{O})$.

Compound 4 (1-acetyl-4-hydroxynaphthalene): acetyl chloride $(2.4 \mathrm{~g}, 30.8 \mathrm{mmol})$ is dissolved in anhydrous nitromethane $(10.0 \mathrm{ml})$ and, while stirring, added drop wise to a mixture of 1-naphthol (4.0 g, $27.8 \mathrm{mmol})$ and zinc chloride ( $4.0 \mathrm{~g}, 29.3 \mathrm{mmol})$ in anhydrous nitromethane $(40.0 \mathrm{ml})$ at $0{ }^{\circ} \mathrm{C}$ (ice-bath) with vigorous stirring under anhydrous conditions. After complete addition, the mixture is stirred at $0{ }^{\circ} \mathrm{C}$ for 30 minutes, then the ice bath is removed and the mixture left is stirred at room temperature for $20 \mathrm{~h}$. The reaction mixture is poured onto $300 \mathrm{~g}$ of ice and $12.0 \mathrm{ml}$ of concentrated hydrochloric acid with continuous stirring for 30 minutes. Dichloromethane $(100.0 \mathrm{ml})$ is added and the organic layer is separated, washed with water $(3 \times 100 \mathrm{ml})$ and brine, and finally dried over anhydrous sodium sulfate. Evaporation of the solvent in vacuo affords a light brown solid residue. The residue is purified by chromatography on a silica gel using dichloromethane/ethyl acetate $(20: 1)$ as an eluent to afford a creamy solid $(1.79 \mathrm{~g}, 56 \%$ yield), m.p. $199-200{ }^{\circ} \mathrm{C}, \mathrm{m} / z$ 186.2. ${ }^{1} \mathrm{H} \mathrm{NMR}\left(\mathrm{CDCl}_{3}, 300 \mathrm{MHz}\right)$ $2.72\left(\mathrm{~s}, 3 \mathrm{H}, \mathrm{CH}_{3}\right), 6.28$ (s, $\left.1 \mathrm{H}, \mathrm{OH}\right), 6.83$ (d, J = 7.8 Hz, $1 \mathrm{H}, \mathrm{CH}-3$ $\mathrm{Ar}), 7.55(\mathrm{~m}, J=8.4$ and $6.9 \mathrm{~Hz}, 1 \mathrm{H}, \mathrm{CH}-6 \mathrm{Ar}), 7.65(\mathrm{~m}, J=8.7$ and $6.9 \mathrm{~Hz}, 1 \mathrm{H}, \mathrm{CH}-7 \mathrm{Ar}$ ), 7.96 (d, $J=8.7 \mathrm{~Hz}, 1 \mathrm{H}, \mathrm{CH}-2 \mathrm{Ar}$ ), 8.27 (dm, $J=8.7 \mathrm{~Hz}, 1 \mathrm{H}, \mathrm{CH}-5 \mathrm{Ar}$ ), 9.04 (dt, $J=8.7$ and $0.6 \mathrm{~Hz}, 1 \mathrm{H}, \mathrm{CH}-8 \mathrm{Ar}$ ). The chemical shifts are almost identical to those given in ref. 14 . ${ }^{13} \mathrm{C} \mathrm{NMR}\left(\mathrm{CDCl}_{3}, 75 \mathrm{MHz}\right), 29.57\left(\mathrm{CH}_{3}\right), 107.06$ (C-3), 122.06 (C-1), 124.78 (C-4a), 126.07 (C-6), 126.64 (C-8), 127.82 (C-6), 129.20 (C-7), 131.96 (C-2), 132.98 (C-8a), 156.13 (C-4), $200.42(\mathrm{C}=\mathrm{O})$. However, the claimed compound to be used for comparison ${ }^{15}$ turned out to be 2-acetyl-1-hydroxynaphthalene.

\section{Spectral investigations}

The UV-Vis spectral measurements were performed on a JASCO V-570 UV-Vis-NIR spectrophotometer, equipped with a Huber MPC-K6 thermostat (precision $1{ }^{\circ} \mathrm{C}$ ), in spectral-grade solvents. The concentration effects were studied in acetonitrile and methanol, keeping the product of cell thickness $(b)$ and total compound concentration (c) constant by using cells with a thickness varying from 0.1 to $10 \mathrm{~cm}$. Diluted solutions of 9597\% sulfuric acid (pure for analysis) were used for protonation in acetonitrile and methanol. Deprotonation was performed by the addition of $\mathrm{NaOH}$ (in methanol) or $\mathrm{NH}_{4} \mathrm{OH}$ (in acetonitrile). The $\mathrm{pH}$ values were measured using a Metrohm $654 \mathrm{pH}$ meter.

Quantitative analysis of deprotonation and aggregation was performed by using a "fishing net" algorithm, for which the mathematical background and applications have already been described in ref. 16 . The results have been statistically verified according to ref. 17.

\section{X-ray measurements}

Single crystals of compound 3 were obtained from methanol at room temperature after crystallization for 9 days. The obtained compound crystallizes as colorless needles in the monoclinic space group $P 2_{1} / n$ (No. 14). The structure was solved using the program Shelx $2014,{ }^{18}$ and revealed formation of pairs of molecules via hydrogen bonding in the solid state (Fig. 2 and 3). The electron density map (Fig. S1-S3, ESI $\dagger$ ) clearly shows a disorder of aldehyde and acid functions. This is due to oxidation of the aldehyde in air into the corresponding acid. Indeed, the position of the carbonyl oxygen atom of the aldehyde superposes with the one from the acid function, while the $\mathrm{H}$-atom of the aldehyde and the OH-group of the acid are also almost superimposed. The relative amounts of aldehyde versus acid have been best refined as 60:40 (see the ESI $\dagger$ ). The hydrogen bond distance between O1\#1 (\#1 -x+1,-y+1,-z+1) and O3 is 2.599(5) A. Compared to the mean plane of the aromatic ring, the aldehyde-acid group is in the plane. The pairs of molecules arrange into chains along the $c$-axis direction (Fig. S4, ESI $\dagger$ ) and further packing along the $b$-axis is shown in Fig. S5 (ESI $\dagger$ ) CCDC 1043758 (3).

\section{Quantum-chemical calculations}

Quantum-chemical calculations were performed by using the Gaussian 09 program suite. ${ }^{19}$ If not explicitly described, the M06-2X functional $^{20}$ with def2-TZVP basis set was used. ${ }^{21}$ This fitted hybrid meta-GGA functional with $54 \%$ HF exchange is specially developed to describe main-group thermochemistry and the non-covalent interactions, showing very good results by predicting the position of the tautomeric equilibrium in azo naphthols possessing intramolecular hydrogen bonds. ${ }^{22}$ All structures

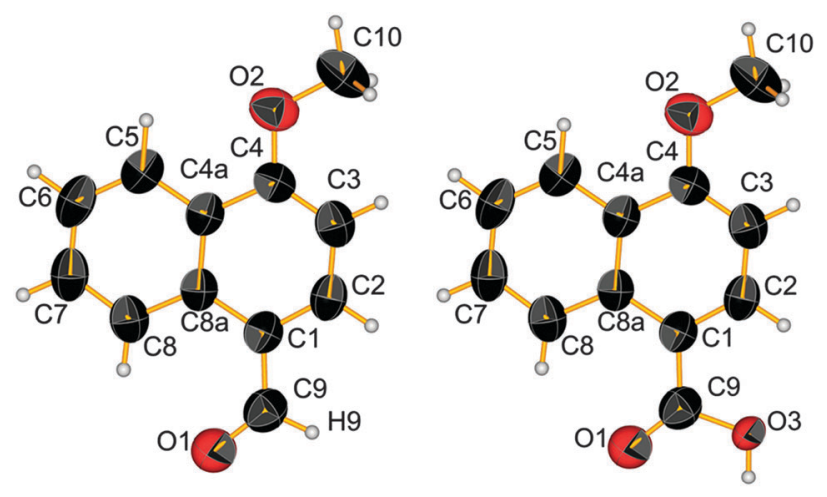

Fig. 2 Ortep representation of the aldehyde form (left) and the acid (right); ellipsoids are drawn with $50 \%$ of probability. 
a)

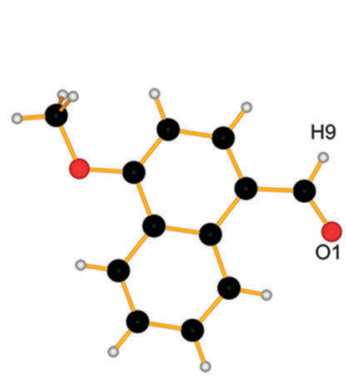

were optimized without restrictions, using tight optimization criteria (with only exception in the modeling dimer associates) and an ultrafine grid in the computation of two-electron integrals and their derivatives, and the true minima were verified by performing frequency calculations in the corresponding environment. Solvent effects are described by using the Polarizable Continuum Model (the integral equation formalism variant, IEFPCM, as implemented in Gaussian 09). ${ }^{23}$

The deprotonation processes were modeled by gradually changing the $\mathrm{O}-\mathrm{H}$ distance $\left(r_{\mathrm{O}-\mathrm{H}}\right)$ in steps of $0.1 \AA$ and optimizing the rest of the molecule at each step. In the case of $\mathbf{1}$ additional constraints (fixing the molecule planar and fixing the $\mathrm{C}-\mathrm{O}-\mathrm{H}$ angle as obtained from the equilibrium geometry in the corresponding solvent environment) were used. The rotational barriers, shown in the ESI, $\uparrow$ were modeled by gradually changing the corresponding dihedral angle in steps of $10^{\circ}$ and optimizing the rest of the molecule at each step. The full counterpoise method ${ }^{24}$ was applied to correct the basis set superposition error (BSSE) on the dimers.

The absorption spectra of the compounds were predicted using the TD-DFT formalism. TD-DFT calculations were carried out using the same functional and the basis set, which is in accordance with conclusions about the effect of the basis set size and the reliability of the spectral predictions. ${ }^{25,26}$

\section{Results and discussion}

The absorption spectra of 1-3 in various solvents are shown in Fig. 4. In toluene all compounds show the same spectral shape - a structured band at $320 \mathrm{~nm}$ in the case of $\mathbf{1}$ and $\mathbf{3}$ and red-shifted absorption at $340 \mathrm{~nm}$ for 2 . In acetonitrile and methanol a new band in the $360-400 \mathrm{~nm}$ region appears in the case of 1 and 2 only. Its strength depends on the solvent and the compound - it is very low in the case of $\mathbf{1}$ in acetonitrile and dominates in $\mathbf{2}$ in methanol. In addition, as will be discussed below, in the case of $\mathbf{1}$ the intensity of this band increases in methanol and acetonitrile with decreasing concentration.

Taking into account that the spectra of 3 (fixed enol) do not change with the solvent, the appearance of this new species for 1 and 2 can be interpreted in the light of two possible processes tautomerism or deprotonation, as shown in Scheme 2. In addition, internal deprotonation through proton transfer is possible in the case of 2 (Scheme 3) as observed in some azonaphthols ${ }^{27}$ and Mannich bases. ${ }^{28-30}$ According to the results obtained from the quantum-chemical calculations, given in Fig. 5, the E-tautomer is much more stable and its stabilization is supported by the intramolecular hydrogen bonding involving the piperidine antenna in 2 . Although the keto tautomer is more polar (for instance: $6.7 \mathrm{D}$

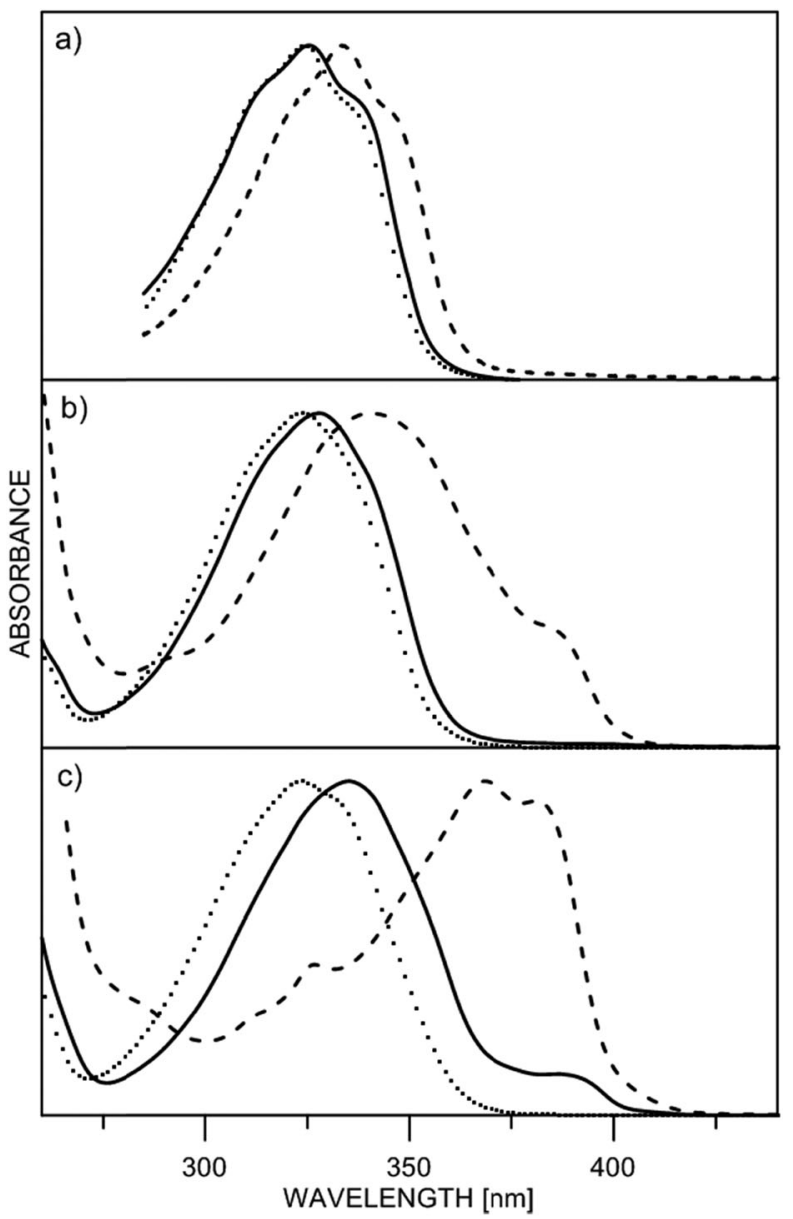

Fig. 4 Normalized absorption spectra of $\mathbf{1}$ (solid line), $\mathbf{2}$ (dashes) and $\mathbf{3}$ (dots) in toluene (a), acetonitrile (b) and methanol (c). 
<smiles>[R]C(=O)c1cc([R])c([O-])c2ccccc12</smiles>

$\mathbf{E}^{-}$

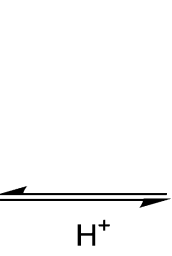

$\mathrm{H}^{+}$<smiles>[R]C(=O)c1cc([R])c(O)c2ccccc12</smiles><smiles>[R]C1=CC(=C([R])O)c2ccccc2C1=O</smiles>

K

Scheme 2 Deprotonation (left) and tautomerism (right) in 1, 2 and 4.<smiles>CCCCN1COc2c(cc(C=O)c3ccccc23)C1</smiles>

2E<smiles>CCCC[NH+]1C[OH+]c2c(cc(C=O)c3ccccc23)C1</smiles>

2PT

Scheme 3 Intramolecular proton transfer in $\mathbf{2}$

against $4.3 \mathrm{D}$ in $\mathbf{1}$ in gas phase) the effect of the solvent polarity does not provide conditions for shifting the equilibrium towards the latter. In addition to that, the content of the component absorbing at $380 \mathrm{~nm}$ is substantially higher in the case of 2, which seems impossible in the light of the proven enol stabilizing action of the piperidine antenna. ${ }^{7}$ Going further - even if the keto form of 2 (2K) would be stabilized somehow and exists in methanol and acetonitrile, the addition of acid would further boost this process, as suggested in Fig. 5 and results in other, structurally similar tautomeric systems. ${ }^{7,9,11}$ Upon addition of acid the absorption spectra of $\mathbf{1}$ and $\mathbf{2}$ in methanol or in acetonitrile show no rise, but disappearance of the band at $380 \mathrm{~nm}$ and restoration of the original band at 320-340 nm occur (see Fig. 6 for 2). The fact that this happens in both compounds is clear evidence that no tautomerism, but

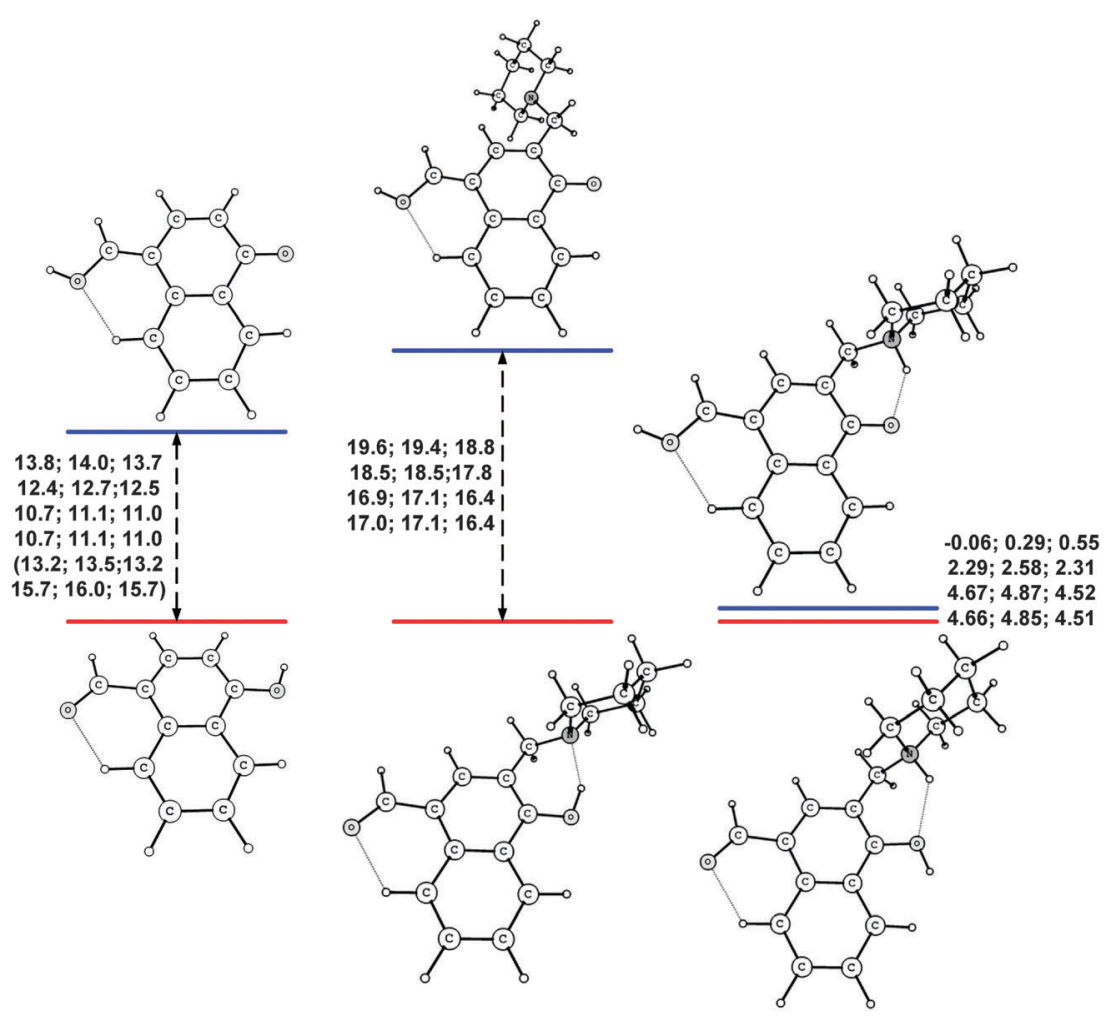

Fig. 5 Predicted relative stability (M06-2X/def2-TZVP) of the tautomers of $\mathbf{1} \mathbf{2}$ and $\mathbf{2} \mathbf{H}^{+}$in the gas phase, toluene, acetonitrile and methanol. Each row shows the relative energy $\left(\Delta E=E_{\mathrm{K}}-E_{\mathrm{E}}\right), \Delta E+\mathrm{ZPE}$ and $\Delta G(298 \mathrm{~K})$ values in the corresponding solvent in $\mathrm{kcal} \mathrm{mol}^{-1}$ units. The energy gaps are scaled according to the gas phase results. The values for 1 in the gas phase using HF and MP2 are given in parentheses. In the figure the most stable isomers of each tautomer are presented, for details see Part 2 of the ESI.† 


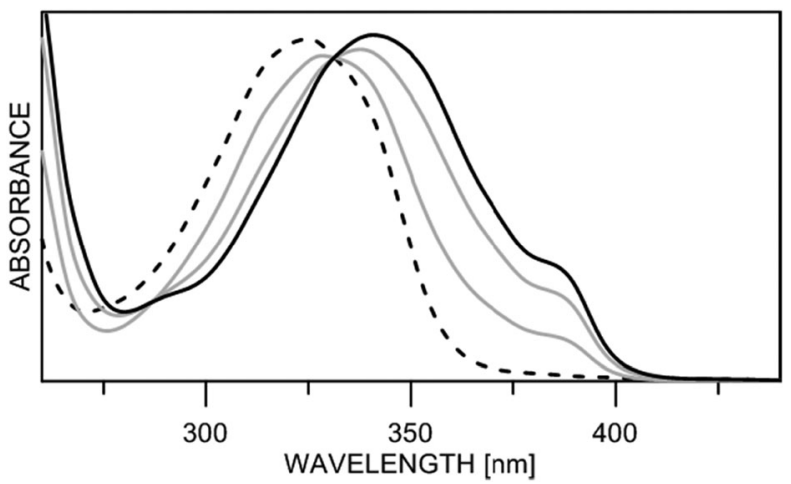

Fig. 6 Absorption spectra of 2 in acetonitrile upon addition of $\mathrm{H}_{2} \mathrm{SO}_{4}$ : $\mathrm{pH}=6.9$ (solid black line, 27\% deprotonated form), 4.8, 4.0, 3.5 (dashes).

a protonation equilibrium is originally observed in solution. At the same time, there are no spectral changes in the case of 3 , in which the relevant hydrogen atom is replaced by a methyl group, at the same $\mathrm{pH}$ interval.

In order to supplement the information already obtained from UV spectra, NMR spectra have been recorded in the same solvents in order to characterize the various species, the $\mathbf{E}^{-}, \mathbf{E}$ and PT-forms. ${ }^{13} \mathrm{C}$ NMR data are given in Table 1 . The ${ }^{13} \mathrm{C}$ spectrum of 2 in toluene is similar to that of the E-form, whereas that in $\mathrm{CD}_{3} \mathrm{OD}$ is close to that of the deprotonated form. In $\mathrm{CDCl}_{3}{ }^{13} \mathrm{C}$ chemical shifts slightly different from those in toluene- $\mathrm{d}_{8}$ are obtained (Table 1), whereas in $\mathrm{CD}_{3} \mathrm{CN}$ characteristic variations are seen. Addition of base to the sample in $\mathrm{CD}_{3} \mathrm{OD}$ as well as low temperature spectra of 2 in $\mathrm{CDCl}_{3}$ have also been recorded, the latter in the temperature interval from $298 \mathrm{~K}$ to $213 \mathrm{~K}$ (Table 1 ).

In the ${ }^{1} \mathrm{H}$ spectrum of 2 in $\mathrm{CD}_{3} \mathrm{CN}$ by adding trifluoroacetic acid, a three-bond coupling between $\mathrm{CH}_{2}$ and the $\mathrm{NH}$ proton at $5.2 \mathrm{~Hz}$ is observed showing that slow exchange is taking place, but also giving an indication of the amount of the proton transferred. In the case of $\mathbf{1}$ no distinct changes are found in the chemical shift of the aldehyde proton upon adding methanol, indicating that the aldehyde group is not involved in tautomerism.

The ${ }^{1} \mathrm{H}$ NMR spectrum of 2 at ambient temperature shows a resonance at $\sim 12.5 \mathrm{ppm}$. The position is very dependent on moisture in the sample. Upon cooling the resonance moves to $14.5 \mathrm{ppm}$ in $\mathrm{CDCl}_{3}(193 \mathrm{~K})$, whereas the signal in $\mathrm{CD}_{2} \mathrm{Cl}_{2}$ moves from $12.4 \mathrm{ppm}$ (ambient) to $12.8(243 \mathrm{~K}), 13.05$ (223 K), $14.2 \mathrm{ppm}(203 \mathrm{~K})$ and $14.45 \mathrm{ppm}(193 \mathrm{~K})$, the resonance becoming gradually broader. In acetonitrile the situation is different. At ambient temperature the resonance is at $12.65 \mathrm{ppm}$, whereas at $243 \mathrm{~K}$ the position is $12.75 \mathrm{ppm}$, which means virtually no change.

In all cases the flipping of the piperidine ring stops at low temperature leading to distinct resonances at $3.10 \mathrm{ppm}(\mathrm{d}, 2 \mathrm{H})$, 2.31 (triplet, $2 \mathrm{H}$ ), $1.93 \mathrm{ppm}$ (triplet like, $1 \mathrm{H}$ ), 1.70 (triplet, $2 \mathrm{H}$ ) and 1.70 (two broad triplet, $3 \mathrm{H}$ ) and $1.22 \mathrm{ppm}(\mathrm{m}, 1 \mathrm{H})$.

Having established that no aggregation of 2 occurs at ambient temperature (no variation in the absorption spectra with the concentration) and in acetonitrile two different UV-Vis bands are clearly observed (Fig. 4), and an equilibrium exists between the E- and PT-forms. This equilibrium is shifted further towards the PT-form in methanol- $\mathrm{d}_{4}$ as judged from the ${ }^{13} \mathrm{C}$ NMR spectrum. One question also raised by Limbach et $a l^{31}$ is the change in the $\mathrm{XH}$ chemical shift towards higher frequencies upon cooling in freons. Is this just due to a strengthening of the hydrogen bond and an elongation of the $\mathrm{XH}$ bond or is this due to the presence of a tautomeric equilibrium? Analyzing the ${ }^{13} \mathrm{C}$ NMR data of Table 1 it is obvious that the chemical shifts of 2 in $\mathrm{CD}_{3} \mathrm{CN}$ is in between those in toluene- $\mathrm{d}_{8}$ (which are very similar to those in $\mathrm{CDCl}_{3}$ ) and those in methanol- $\mathrm{d}_{4}$. This together with the changes in the ${ }^{1} \mathrm{H}$ XH chemical shifts and the UV observations suggests that in toluene and $\mathrm{CDCl}_{3}$ the enolform is dominant $(2.5: 1)$ as suggested previously, whereas in $\mathrm{CD}_{3} \mathrm{CN}$ there is a tautomeric equilibrium but the enol form is dominant. In methanol- $\mathrm{d}_{4}$ the PT-form is dominant as can be seen by comparing the ${ }^{13} \mathrm{C}$ data for the anion.

Having established that in methanol the PT-form dominated for 2, the NMR parameters of the PT-form are now known (Table 1). The NMR parameters for the E-form can be measured

Table 1 Experimentally measured ${ }^{13} \mathrm{C}$ chemical shifts of 2

\begin{tabular}{|c|c|c|c|c|c|c|c|}
\hline & Toluene- $\mathrm{d}_{8}$ & $\mathrm{CDCl}_{3}$ & $\mathrm{CDCl}_{3} 213 \mathrm{~K}$ & $\mathrm{CD}_{3} \mathrm{CN}$ & $\mathrm{CD}_{3} \mathrm{OD}$ & $\mathrm{CD}_{3} \mathrm{OD}+$ base $^{a}$ & $\mathrm{CD}_{3} \mathrm{CN}+\operatorname{acid}^{b}$ \\
\hline $\mathrm{C}-1$ & 123.7 & 122.5 & $120.1(2.4)^{c}[0.8]^{d}$ & 122.0 & 118.4 & 115.7 & 125.5 \\
\hline $\mathrm{C}-2$ & 138.5 & 138.9 & $141.0(-2.1)[0.5]$ & 141.2 & 145.4 & 148.1 & 142.7 \\
\hline $\mathrm{C}-3$ & 112.9 & 112.7 & $111.2(1.5)[2.0]$ & 113.5 & 111.5 & 119.2 & 114.6 \\
\hline $\mathrm{C}-4$ & 161.3 & 162.2 & $165.2(-3.0)[-2.9]$ & 165.3 & 174.3 & 177.6 & 160.0 \\
\hline C-5 & 123.0 & 122.7 & $122.7(0)[-0.1]$ & 123.8 & 125.3 & 126.3 & 123.6 \\
\hline C-6 & 126.0 & 125.8 & $125.4(0.4)[0.4]$ & 126.6 & 125.8 & 124.6 & 128.1 \\
\hline $\mathrm{C}-7$ & 129.4 & 129.3 & $129.5(-0.2)[0]$ & 130.1 & 130.6 & 129.6 & 131.5 \\
\hline C-8 & 125.2 & 124.5 & $124.5(0)[0.1]$ & 125.4 & 125.8 & 125.6 & 125.9 \\
\hline $\mathrm{C}-4 \mathrm{a}$ & 125.7 & 125.2 & $125.6(-0.4)[-0.2]$ & 126.4 & 129.8 & 131.3 & 126.0 \\
\hline $\mathrm{C}-8 \mathrm{a}$ & 132.4 & 131.9 & $131.8(0.1)[-0.1]$ & 132.9 & 135.3 & 135.5 & 133.8 \\
\hline $\mathrm{CHO}$ & 190.6 & 191.6 & $192.0(-0.4)[0.2]$ & 192.3 & 192.1 & 190.9 & 193.1 \\
\hline $\mathrm{CH} 2$ & 61.6 & 61.7 & 61.4 & 61.9 & 60.9 & 58.3 & 56.9 \\
\hline $\mathrm{C}-2^{\prime}, 6^{\prime}$ & 53.6 & 53.6 & 53.1 & 54.0 & 53.8 & 55.1 & 54.4 \\
\hline $\mathrm{C}-3^{\prime}, 5^{\prime}$ & 25.9 & 25.6 & 25.0 & 26.3 & 25.2 & 26.7 & 23.7 \\
\hline $\mathrm{C}-4^{\prime}$ & 24.0 & 23.7 & 23.0 & 24.2 & 23.5 & 25.5 & 22.2 \\
\hline
\end{tabular}

${ }^{a}$ Potassium $t$-butoxide. ${ }^{b}$ Trifluoroacetic acid is added. ${ }^{c}$ Difference between chemical shifts at $298 \mathrm{~K}$ and $213 \mathrm{~K}$. ${ }^{d}$ Calculated chemical shifts for a lengthening of $0.1 \AA$ A piperidine unit carbon atoms are designated as prime $(')$. 
in toluene- $\mathrm{d}_{8}$ (Table 1). The data for $\mathrm{CDCl}_{3}$ and for $\mathrm{CD}_{3} \mathrm{CN}$ are seen to lie in between with those of $\mathrm{CD}_{3} \mathrm{CN}$ mostly towards the 2PT. In $\mathrm{CDCl}_{3}$ the change in ${ }^{13} \mathrm{C}$ chemical shifts upon decreasing the temperature can be analysed in terms of an $\mathrm{XH}$ bond length change as the changes are not similar to those caused by a change in the tautomeric equilibria. A good correlation is found between the observed and calculated changes (Table 1).

The process of deprotonation in $\mathbf{1}$ and $\mathbf{2}$ is, as expected, backed by the electron acceptor nature of the $\mathrm{CHO}$ group, on one side. The spontaneous deprotonation of 4-nitronaphthalen-1-ol and related compounds, leading to equilibrium between neutral and deprotonated forms in organic solvents, has been reported already in the literature. ${ }^{32}$ On the other side, the nitrogen atom from the piperidine unit in $\mathbf{2}$ is actually an attached base, which makes the intramolecular proton relocation from $\mathrm{O}$ to $\mathrm{N}$ relatively easy. Such internal deprotonation in Mannich bases is also known. ${ }^{28}$

The deprotonation of $\mathbf{1}$ and $\mathbf{2}$ in acetonitrile is illustrated in Fig. 7. The addition of base leads to an increase of the band at $380 \mathrm{~nm}$ till complete deprotonation. The corresponding $\mathrm{p} K_{\mathrm{a}}$ values, determined spectrophotometrically using the methodology described in ref. 17, are as follows: $9.09 \pm 0.08$ and $8.57 \pm 0.07$ for 1 in acetonitrile and methanol. These data are in good agreement with the value of $6.36^{32,33}$ reported for 4-nitronaphthalen-1-ol in the ethanol-water mixture, taking into account the difference in the electron acceptor nature of the $\mathrm{CHO}$ and $\mathrm{NO}_{2}$ groups and the different media. Compound 2 is practically fully deprotonated in methanol and has a $\mathrm{p} K_{\mathrm{a}}$ value of $8.4 \pm 0.1$ in acetonitrile. As seen, the proton can be lost much more easily in the case of 2

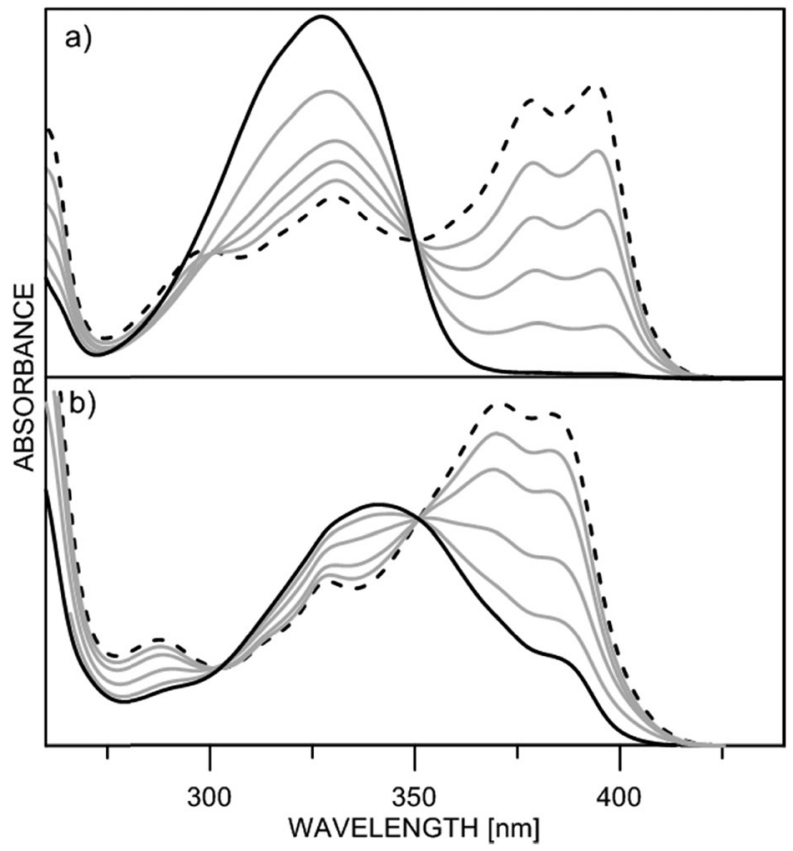

Fig. 7 Absorption spectra of $\mathbf{1}$ (a) and $\mathbf{2}$ (b) in acetonitrile upon the addition of $\mathrm{NH}_{4} \mathrm{OH}$ : (a) $\mathrm{pH}=7.01$ (solid black line, $1 \%$ deprotonated form), 8.57, 8.93, 9.04, 9.37, 9.68 (dashes, 85\% deprotonated form); (b) $\mathrm{pH}=7.09$ (solid black line, 27\% deprotonated form), 8.36, 8.51, 9.06, 9.28, 9.59 (dashes, fully deprotonated). and also in methanol, compared to acetonitrile. In Fig. 8 the deprotonation of $\mathbf{1}$ was modeled by changing gradually the $\mathrm{O}-\mathrm{H}$ distance. Starting from the minimum at $0.962 \AA$ in the gas phase the removal of proton needs substantial energy and this energy does not depend on the solvent environment as described by the PCM model. The addition of a solvent molecule, which plays a role of a proton acceptor, facilitates the process most substantially in the case of methanol. These results match nicely with the absorption spectra of 1 in Fig. 4 - no deprotonation band in toluene, a very weak one in acetonitrile and a noticeable one in methanol, confirming the role of the solvent in the process. The absorption spectra suggest that the proton is lost much more easily in the case of 2 , which is also supported by the quantumchemical results shown in Fig. 9. In this case the piperidine nitrogen atom participates as an attached base, attracting and accepting the proton. As seen in the gas phase and in toluene this intramolecular O-N proton transfer does not occur, but in acetonitrile and in the methanol solvent environment a stable deprotonated form is obtained at the $\mathrm{O}-\mathrm{H}$ distance of $1.7 \AA$ with a relative energy of $1.17 \mathrm{kcal} \mathrm{mol}^{-1}$ in methanol and $1.13 \mathrm{kcal} \mathrm{mol}^{-1}$ in acetonitrile. It is worth noticing that the proton transfer does not involve the $\mathrm{O}-\mathrm{H}$ distance only. As seen from Fig. 9, right, the transfer of the proton is accompanied by a change in the $\mathrm{O}-\mathrm{N}$ distance (and also structural changes in the whole molecule) with a minimum value at $r_{\mathrm{O}-\mathrm{H}}=1.3 \AA$, which corresponds to the inflection point in Fig. 9 left. At this point the proton is actually transferred from the oxygen to the nitrogen atom.

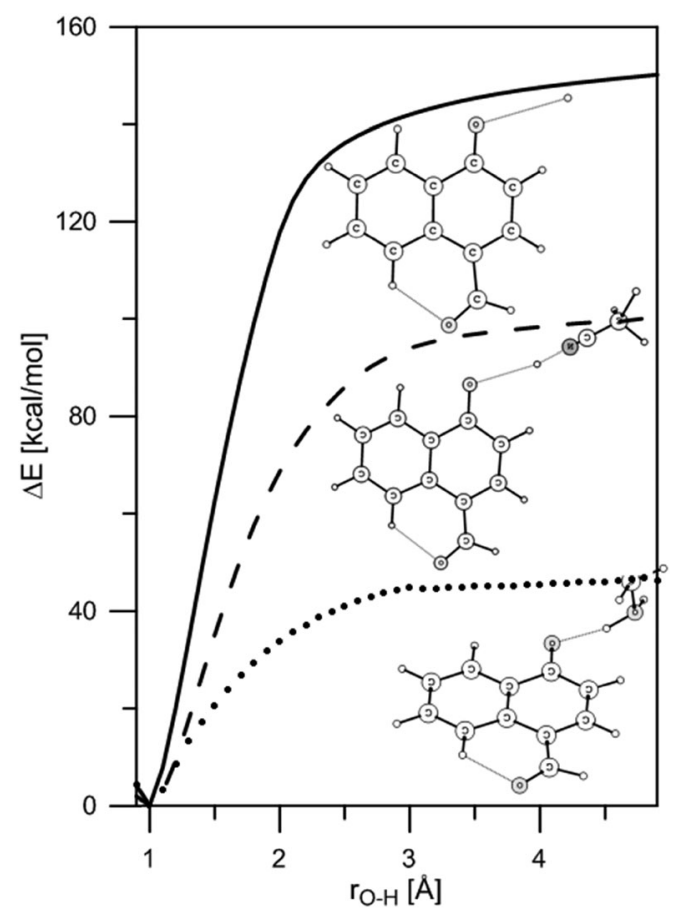

Fig. 8 Theoretically predicted potential energy curves for the deprotonation of 1 in the gas phase (lines) and interacting with an acetonitrile molecule in an acetonitrile environment (dashes) and a methanol molecule in a methanol environment (points). The deprotonation in toluene, acetonitrile and methanol without participation of a solvent molecule leads to essentially the same results as in the gas phase. 


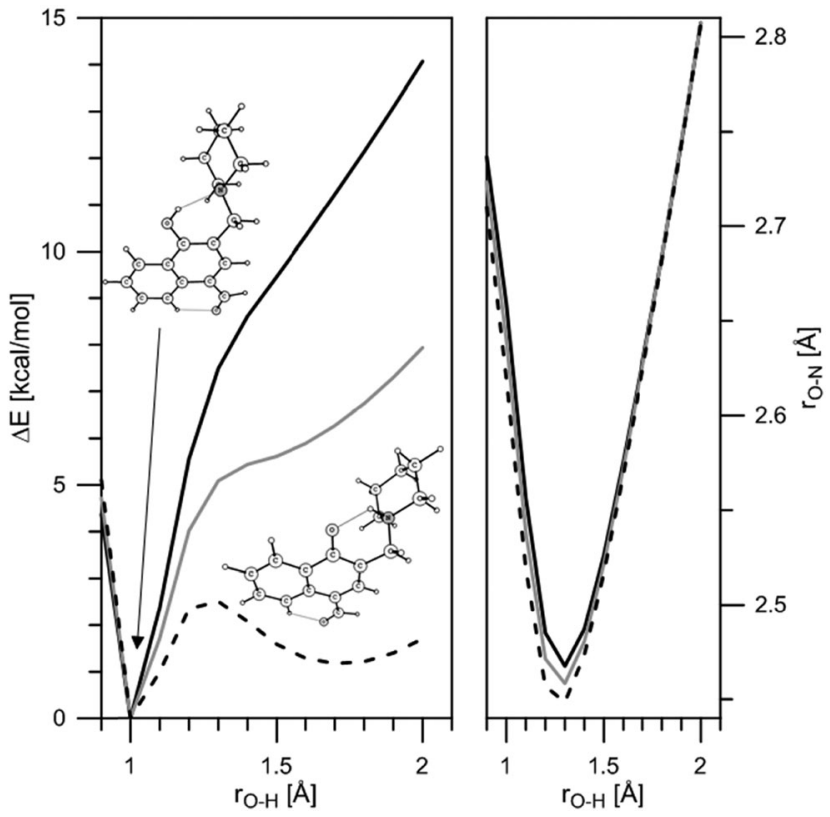

Fig. 9 Theoretically predicted potential energy for intramolecular deprotonation of $\mathbf{2}$ in the gas phase (black solid lines), toluene (gray lines), acetonitrile and methanol (dashes) presented as a function of $r_{\mathrm{O}-\mathrm{H}}$ (left). Dependence between $r_{\mathrm{O}-\mathrm{H}}$ and $r_{\mathrm{O}-\mathrm{N}}$ (right).

The calculated relative stability of the internally deprotonated (zwitterionic) 2PT in acetonitrile and in methanol suggests a measurable amount of deprotonated species in solution, as observed in the absorption spectra, Fig. 4, but does not explain the differences between the solvents. Proton donor and acceptor abilities of these two solvents are rather different ${ }^{34}$ and the strong proton acceptor-donor capacity of methanol allows formation of complexes with the solute that can additionally stabilize one or the other form. In addition to the forms shown in Fig. 9, compound 2 has one more deprotonated form, which is obtained by rotation of the piperidine ring around the spacer in a way that the piperidine nitrogen atom is at the same side as the $\mathrm{CHO}$ group, nearing it (structure $\mathbf{c}$ in the Fig. 10). The situation is clarified in Fig. 10 and the possibilities for specific interactions with the methanol are considered in Fig. 11. The theoretical calculations show that the intramolecular hydrogen bonded forms a and $\mathbf{b}$ can form complexes with methanol through one of the oxygen atoms. The results suggest that the addition of a methanol molecule leads to stabilization of the deprotonated form $\mathbf{b}$ through $\mathrm{C}-\mathrm{O}^{-} \ldots$ HOMe hydrogen bond formation and of the form a through $\mathrm{CH}=\mathrm{O} \cdots \mathrm{HOMe}$ interaction. However, the complex of the $\mathbf{b}$ form is more stable, which reverses the relative energies from Fig. 10 and very nicely corresponds to the spectral observation in methanol solution discussed above. The deprotonated $\mathbf{c}$ isomer offers an additional interaction between the protonated nitrogen atom and the solvent molecule, but all possible complexes are substantially less stable than the $\mathbf{b}$ form and this isomer cannot exist in solution as also proven by the NMR data (ESI $\dagger$ ). It is worth noting that the scheme given in Fig. 11 is very simplified and does not describe the overall complexity in solution, but it shows the

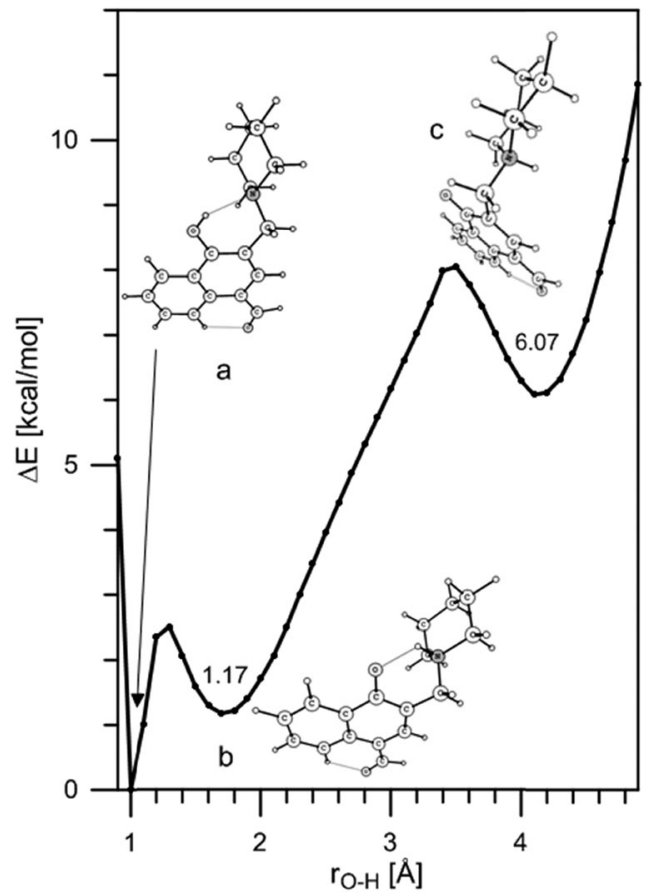

Fig. 10 Theoretical description of the rotation of the piperidine ring as a function of the $r_{\mathrm{O}-\mathrm{H}}$ distance in the methanol environment.

trend toward stabilization of the $\mathbf{b}$ form, explaining its predominance in solution as proven by the spectral data.

As was mentioned above, the absorption spectra of $\mathbf{1}$ are concentration dependent in both acetonitrile and methanol, as the effect in methanol is more pronounced. The only visual effect of this dependence is the rise of the band of the deprotonated form upon dilution and a slight decrease of the intensity at 320-330 nm (Fig. 12a). Obviously 1 forms aggregates in solution and their breakup upon dilution facilitates the process of deprotonation. If we assume the simplest case of association in the used concentration region, namely dimerization, the spectral behavior does not allow making clear conclusions about the structure of the dimers. The nearest example is the dimerization of 4-methoxy and 4-ethoxy benzaldehydes, which has been studied in combination between theoretical and experimental (IR and NMR) methods. ${ }^{35}$ However, the experimental results do not allow the structure of the dimers to be explicitly defined except if crystallographic data are available. In this case, due to the fact that there is no $\mathrm{OH}$ group, the theoretical calculations suggest a variety of cyclic dimers involving the $\mathrm{CHO}$ group and/or the neighbor aromatic $\mathrm{C}-\mathrm{H}$ atoms, whose relative stability strongly depends on the level of the theory used. The replacement of the benzene ring with naphthalene in 1 and the availability of the free $\mathrm{OH}$ group provide four main types, presented in Fig. 13, of dimers to be formed. It should be noted that the arrangement of the $\mathrm{C}=\mathrm{O}$ group towards the neighboring $\mathrm{C}_{8}-\mathrm{H}$ in the same molecule substantially reduces the possibility of formation of cyclic dimers via the aromatic $\mathrm{CH}$ atoms of the second molecule (as in the benzaldehydes discussed above) and such dimers are not found to be stable enough by the theoretical calculations. 


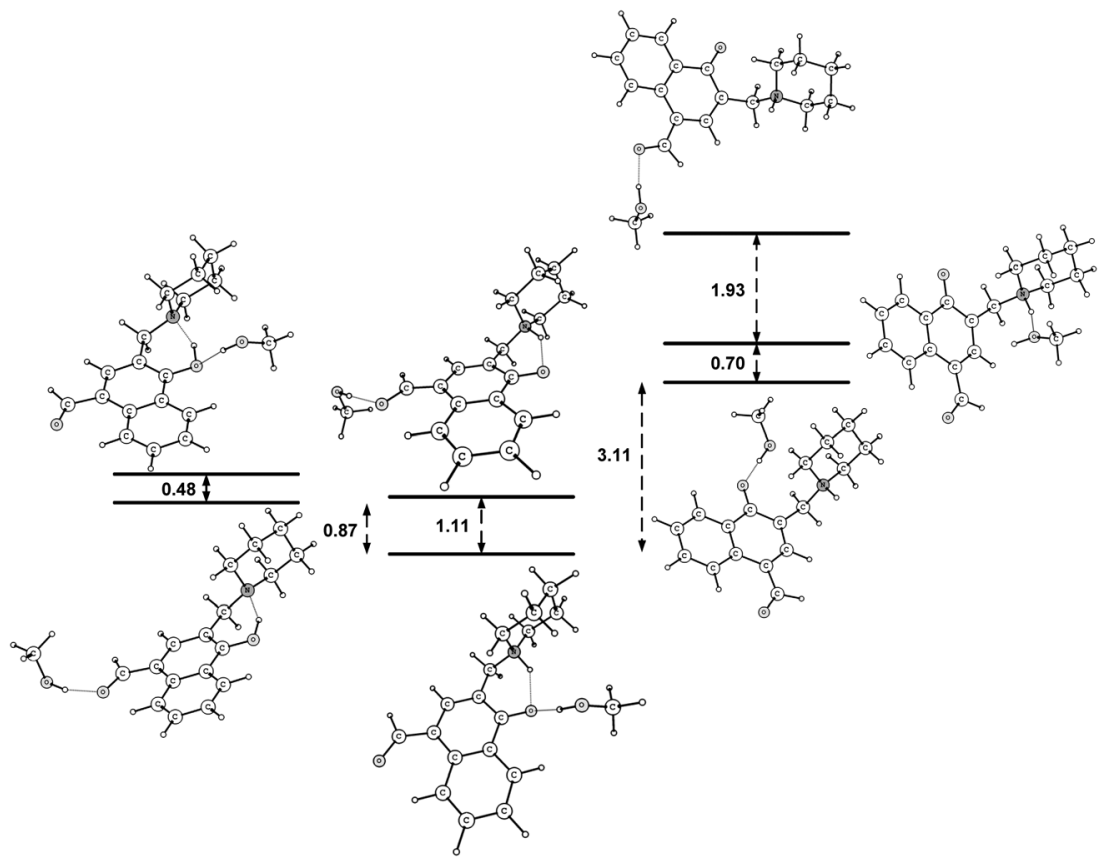

Fig. 11 Predicted relative stability (M06-2X/def2-TZVP, in kcal mol ${ }^{-1}$ ) of the 1:1 complexes of 2 with methanol (from left to right a, b, c, see Fig. 10) optimized in the methanol environment.

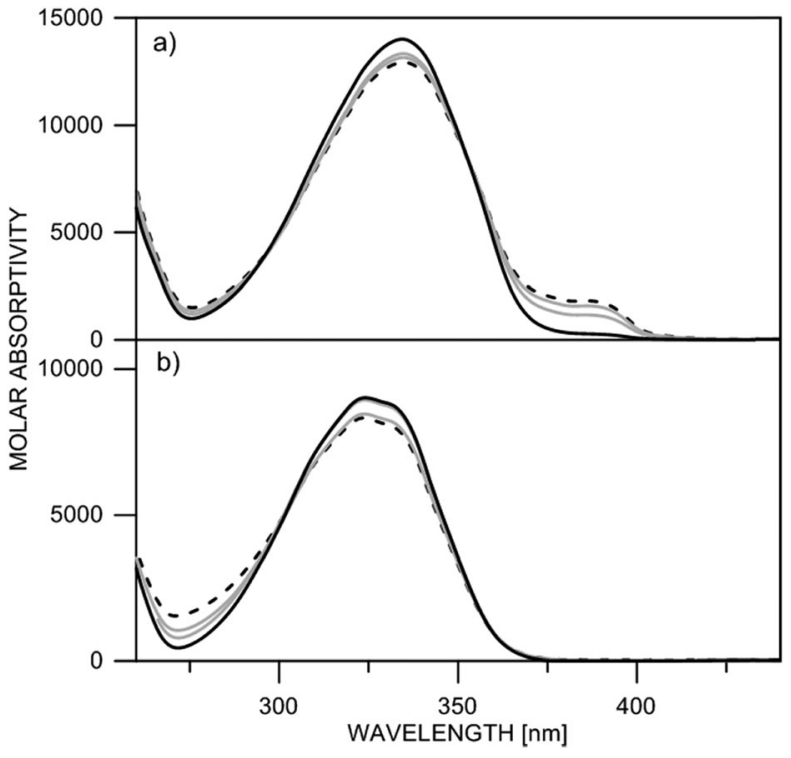

Fig. 12 Concentration dependent spectra of 1 (a) and $\mathbf{3}$ (b) in methanol: solid line $-7 \times 10^{-4} \mathrm{M}$, dashes $-7 \times 10^{-6} \mathrm{M}$.

Each of the dimers, shown in Fig. 13, represents the most stable structure from a large number of possible similarities involving isomers of $\mathbf{1}$ with respect to the orientation of the CHO group (syn-anti, see Table S3, ESI $\dagger$ ). Two of these dimers are formed on the basis of hydrogen bonding involving the $\mathrm{OH}$ group, which on the first glimpse relates them to the deprotonation process. However, the $\pi-\pi$ sandwich dimer can also sterically hamper deprotonation, taking into account the active action of the solvent in this process (Fig. 8).

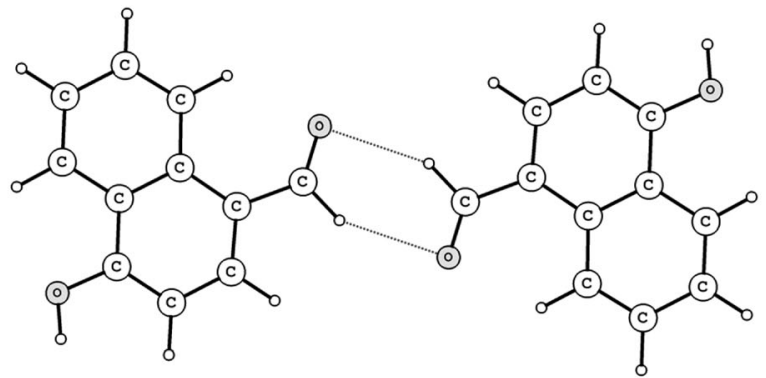

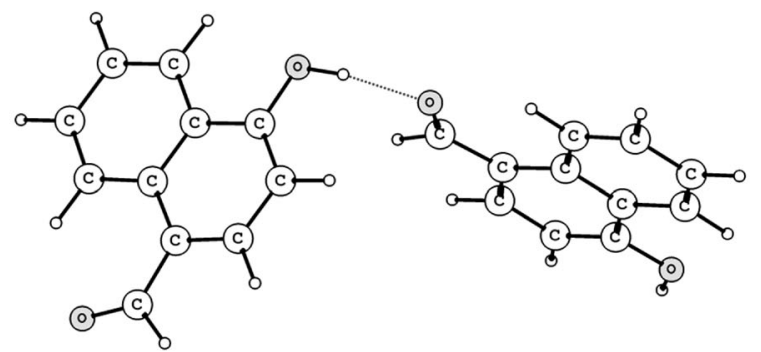
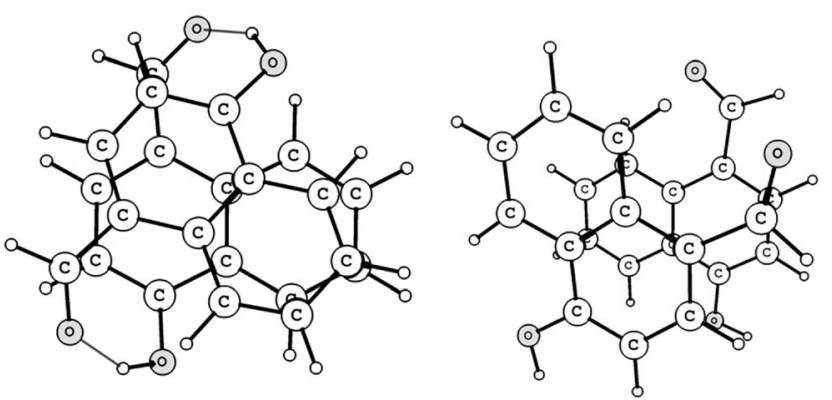

Fig. 13 Representative theoretical models of the dimers of 1: from top to bottom - cyclic, head to tail and sandwich (left: $\mathrm{H}$-bonded; right: $\pi-\pi$ stacked). 
Table 2 Stabilization energies of the dimers of 1 and predicted longwavelength bands in the gas phase

\begin{tabular}{|c|c|c|c|}
\hline \multirow[b]{2}{*}{ Structure } & \multirow[b]{2}{*}{$\begin{array}{l}\Delta E^{a} \\
{\left[\mathrm{kcal} \mathrm{mol}^{-1}\right]}\end{array}$} & \multicolumn{2}{|c|}{ Long-wavelength bands } \\
\hline & & $\begin{array}{l}\lambda_{\max } \\
{[\mathrm{nm}]}\end{array}$ & $\begin{array}{l}\text { Oscillator } \\
\text { strength }\end{array}$ \\
\hline 1 & 0.0 & $\begin{array}{l}289 \\
296^{c} \\
297^{d} \\
297^{e}\end{array}$ & $\begin{array}{l}0.218 \\
0.318^{c} \\
0.312^{d} \\
0.309^{e}\end{array}$ \\
\hline $\mathbf{1}^{-}$ & - & $\begin{array}{l}330 \\
296 \\
336^{c} \\
295^{c} \\
331^{d} \\
289^{d} \\
331^{e} \\
289^{e}\end{array}$ & $\begin{array}{l}0.233 \\
0.158 \\
0.396^{c} \\
0.207^{c} \\
0.383^{d} \\
0.166^{d} \\
0.379^{e} \\
0.165^{e}\end{array}$ \\
\hline 2 & - & 298 & 0.217 \\
\hline 3 & - & 289 & 0.246 \\
\hline Cyclic dimer of $\mathbf{1}$ & $3.2(3.2)^{b}$ & 292 & 0.558 \\
\hline Sandwich $\pi-\pi$ dimer of $\mathbf{1}$ & $10.3(10.2)^{b}$ & $\begin{array}{l}301 \\
300\end{array}$ & $\begin{array}{l}0.046 \\
0.086\end{array}$ \\
\hline Head-to-tail dimer of $\mathbf{1}$ & $10.4(10.4)^{b}$ & 300 & 0.371 \\
\hline Sandwich dimer of 1 & $13.9(13.9)^{b}$ & $\begin{array}{l}332 \\
322\end{array}$ & $\begin{array}{l}0.026 \\
0.093\end{array}$ \\
\hline
\end{tabular}

${ }^{a}$ Stabilization energy, calculated with respect to the doubled value for 1 $\left(\Delta E=2 E_{1}-E_{\text {dimer }}\right)$. Positive value indicates stabilization with respect to the monomer. ${ }^{b}$ Using BSSE correction. ${ }^{c}$ In toluene. ${ }^{d}$ In acetonitrile. ${ }^{e}$ In methanol.

The corresponding stabilization energies, as estimated by the theoretical calculations, are summarized in Table 2, showing that the cyclic dimers are much less stable than the head to tail and sandwich ones. The theoretical calculations predict, taking into account that the M06-2X functional systematically underestimates $\ddagger$ the band positions ${ }^{26}$ a long-wavelength maximum at $360-400 \mathrm{~nm}$, which corresponds to the deprotonated form, the maximum at $320-340 \mathrm{~nm}$ is related to the existing strong associates§ in solution and the monomer species could be expected to absorb around $290 \mathrm{~nm}^{36}$

The limited spectral changes from Fig. 12a need additional information to be connected with the theoretical structures from Fig. 13. This additional information is found in the spectral behavior of structures 2-4. The spectra of 3 are concentration dependent with appearance of a shoulder at 290-300 nm upon

\# In order to verify the theoretical results the absorption maxima were predicted by using the PBE0 functional in addition. The corresponding results, shown in Table S4 (ESI $\dagger$ ), confirm the conclusions about the relative positions of the bands. $\S$ The predicted absorption maxima of the dimers, shown in Table 2, need additional explanation. According to exciton theory ${ }^{36}$ the absorption of the sandwich dimer is blue shifted with respect to the monomer. In this particular case (Fig. 12, Table 2) the most stable H-bonded sandwich dimer is nonsymmetric and the so-called $\mathrm{J}$ band dominates. The symmetric sandwich dimer, which is less stable by $1.18 \mathrm{kcal} \mathrm{mol}^{-1}$ (Table S3, ESI + ), has only H-band, which is blue shifted as expected according to theory. dilution. There is no deprotonation in this case and formation of cyclic or $\pi-\pi$ dimers, the absorption maximum of which is red shifted with respect of the isolated monomer (Table 2), is possible. It should be noted here that the steric hindrance of the methyl group probably will substantially reduce the strength of the sandwich dimer compared with that of $\mathbf{1}$. Following the predicted spectral values, the experimentally observed absorbance at 290-300 nm corresponds to the monomer and the band at $330 \mathrm{~nm}$ can be associated with the dimer. The slight spectral changes suggest a potentially large dimerization constant. The data in Fig. 12b were processed as monomer-dimer mixture according to the methodology described in ref. 37, but the slight spectral differences leads only to the rough estimation that the $\log K_{\mathrm{D}}$ value is larger than 6 units. For this reason the spectrum of the pure monomer cannot be recorded. Evidence for a cyclic dimer in $\mathbf{3}$ is seen from crystallographic data. In the solid state, as seen from Fig. 3, symmetric dimers stabilized by weak $\mathrm{C}-\mathrm{H} \cdots \mathrm{O}=\mathrm{C}$ interactions exist.

The spectra of 2 are concentration independent in the concentration range between $5 \times 10^{-6} \mathrm{M}$ and $1 \times 10^{-3} \mathrm{M}$. On one side, the dimers through $\mathrm{OH}$ groups (head to tail and sandwich) are impossible in this case bearing in mind the steric hindrance of the piperidine unit and the involvement of the $\mathrm{OH}$ group in strong intramolecular hydrogen bonding. On the other side, cyclic dimers through aldehyde groups cannot be excluded as well as cyclic dimers involving the deprotonated oxygen and protonated nitrogen in 2PT (Scheme 4). The former cannot be detected through the appearance of the deprotonation peak as in $\mathbf{1}$ since the deprotonation is intramolecular. The latter has been discussed by Limbach et al. ${ }^{30}$ and by Sobczyk ${ }^{38}$ for a similar compound, 2-( $N, N$-diethylaminomethyl)3,4,6trichlorophenol. However, Limbach et al. found dimerization mainly occurred at low temperature and when the solvent as a function of temperature had a high dielectric constant. In order to form a dimer as shown in Scheme 4, the intramolecular hydrogen bond has to be broken and the $\mathrm{NH}$ bond has to be rotated at $180^{\circ}$. As illustrated in Fig. 10 and it is seen to be highly energy demanding and in addition to that entropy non-favored.

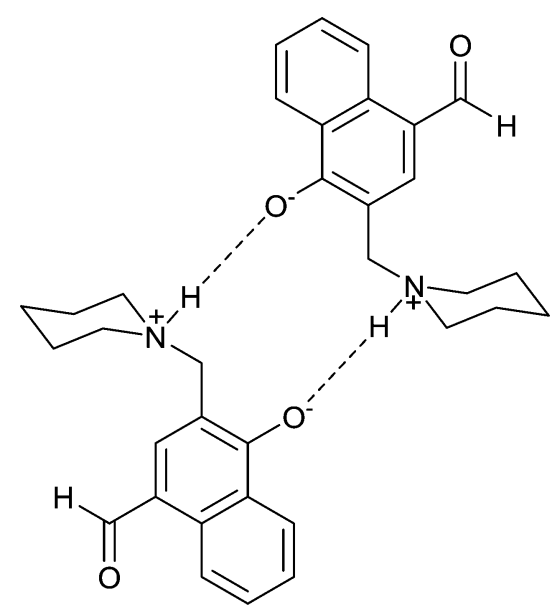

Scheme 4 Sketch of a possible additional type of cyclic dimer of 2PT. 
At ambient temperature both terms cannot be compensated as judged by the Limbach case, but at low temperature the entropy term involved will be less important. Again $\pi-\pi$ dimers are possible, but they should be weak bearing in mind the steric effect of the $\mathrm{CH}_{2}$ spacer.

Compound $\mathbf{4}$ is a suitable model where cyclic dimers are impossible due to the steric hindrance of the methyl group. The computational and experimental data show that deprotonation occurs in methanol and acetonitrile (Fig. S11 and S12, ESI $\dagger$ ), to an extent less than $\mathbf{1}$, but the main band is concentration independent. The less monomer (both neutral and deprotonated) is found probably due to the fact that the $\mathrm{OH}$ group is less acidic than that in $\mathbf{1}$ because the carbonyl group in $\mathbf{4}$ is twisted out of the ring plane. The less acidity of the $\mathrm{OH}$ group and steric hindrance of the methyl group reduce possibilities of formation of head to tail dimers. At the same time the twisted carbonyl group facilitates interactions in the sandwich dimer, which might explain its stability in this case.

Taking into account the discussion above it is very difficult to find clear explanation of the concentration effect in 1. Compounds 1-4 taking into account the similarity in their structures and spectra exist as aggregates in non-polar solvents. In acetonitrile and especially in methanol the dilution in $\mathbf{1}$ leads to deprotonation, which indicates that the $\mathrm{OH}$ group is affected by the aggregation process. This excludes cyclic dimers, which are possible in 2 and 3 . The theoretical data from Table 2 indicate that the cyclic dimer is much less stable compared to the head to tail and sandwich ones. The $\pi-\pi$ stacking dimer is the only structure that satisfies the observed spectral changes in all studied compounds. Although the $\mathrm{OH}$ group is not directly involved in the aggregation, the existence of the dimer hampers the deprotonation process, where the solvent plays active role as shown in Fig. 8. This dimer is probably less stable in the case of 2-4 for steric reasons, but as shown in the experimental data in the case of 3 , the dimerization constant even in this case is large enough to fully shift the equilibrium to the dimer in solution. The real situation in solution is much more complicated, because in acetonitrile and especially in methanol additional stabilization-destabilization of the dimers through solvent interaction with the $\mathrm{OH}$ and $\mathrm{C}=\mathrm{O}$ groups can be expected. In this respect the values for the stabilization energies, given in Table 2, must be considered as indicative.

\section{Conclusions}

The experimental results have shown that there is no tautomerism in the case of $\mathbf{1}$, but deprotonation, influenced by the solvent and the concentration. The detected aggregation is very strong and influences the deprotonation in acetonitrile and in methanol. The most likely $\pi-\pi$ stacking dimer is formed in solution, although in the model compound 3 , a cyclic dimer was proven to exist in the solid state by X-ray measurements. In the case of 2, intramolecular proton transfer (a kind of internal deprotonation) occurs in acetonitrile leading to an almost full deprotonation in methanol. Although the theoretical calculations explain reasonably well the observed spectral changes, the mechanism of deprotonation in $\mathbf{1}$ involving the dimer, needs additional investigations.

Compound $\mathbf{1}$ is not suitable as a tautomeric platform for molecular switching, due to the very large energy gap between enol and keto states, which cannot be overcome with the piperidine sidearm as implemented in 2. A similar behavior has been observed in 4-hydroxyazophenol ${ }^{7}$ and in some azonaphthols containing strong electron acceptor substituents, ${ }^{27}$ where internal deprotonation and formation of a zwitterionic structure is observed instead of tautomeric proton transfer.

\section{Acknowledgements}

The financial support from Bulgarian Ministry of Education and DAAD (joint research project HTC02/227 Proton Cranes), Swiss National Science Foundation (SupraChem@Balkans.eu Institutional partnership project) as well as by Bulgarian National Science Fund (access to MADARA computer cluster by the project RNF01/0110 and to NMR facilities by projects UNA-17/2005 and DRNF-02-13/2009) is gratefully acknowledged.

\section{References}

1 V. Balzani, A. Credi and M. Venturi, Molecular Devices and Machines - Concepts and Perspectives for the Nanoworld, Wiley-VCH, Weinheim, 2008.

2 J. Steed and J. Atwood, Supramol. Chem., Wiley, Chichester, 2009; J. Atwood and J. Steed, Encyclopedia of Supramolecular chemistry, CRC Press, Boca Raton, 2004.

3 P. Franzon, D. Nackashi, C. Amsinck, N. DiSpigna and S. Sonkusale, Molecular Electronics - Devices and Circuits Technology, IFIP International Federation for Information Processing, 2007, 240, 1.

4 Molecular Switches, ed. B. Feringa, Wiley-VCH, Weinheim, 2nd edn, 2011.

5 M. Natali and S. Giordani, Chem. Soc. Rev., 2012, 41, 4010; S. van der Molen and P. Liljeroth, J. Phys.: Condens. Matter, 2010, 22, 133001; F. Raymo, Adv. Mater., 2002, 14, 401; B. Feringa, R. van Delden, N. Koumura and E. Geertsema, Chem. Rev., 2000, 100, 1789; J.-P. Desvergne and H. Bouas-Laurent, Chem. Commun., 1978, 403; D. Leigh, J. Wong, F. Dehez and F. Zerbetto, Nature, 2003, 424, 174.

6 P. Liljeroth, J. Repp and G. Meyer, Science, 2007, 317, 1203; F. Mohn, L. Gross, N. Moll and G. Meyer, Nat. Nanotechnol., 2012, 7, 227.

7 L. Antonov, V. Deneva, S. Simeonov, V. Kurteva, D. Nedeltcheva and J. Wirz, Angew. Chem., Int. Ed., 2009, 48, 7875; L. Antonov, AIP Conf. Proc., 2015, 1642, 449.

8 H. Y. Lee, X. Song, H. Park, M.-H. Baik and D. Lee, J. Am. Chem. Soc., 2010, 132, 12133; A. Farrera, I. Canal, P. HidalgoFernández, L. Pérez-García, O. Huertas and F. Luque, Chem. - Eur. J., 2008, 14, 2277; A. Todorov, M. Nieger and J. Helaja, Chem. - Eur. J., 2012, 18, 7269. 
9 P. J. Taylor, G. van der Zwan and L. Antonov, Tautomerism: Introduction, History and Recent Developments of Experimental and Theoretical Methods, in Tautomerism: Methods and Theories, ed. L. Antonov, Wiley-VCH, Weinheim, 2013.

10 L. Antonov, V. Kurteva, S. Simeonov, V. Deneva, A. Crochet and K. Fromm, Tetrahedron, 2010, 66, 4292.

11 V. Deneva, Y. Manolova, L. Lubenov, V. Kuteva, F. Kamounah, R. Nikolova and B. Shivachev, J. Mol. Struct., 2013, 1036, 267.

12 W. Gross, D. Oberkobusch and R. Nemitz, Henkel AG \& Co. KGAA, Agent for dyeing keratin-containing fibers, US Pat., 2010/0064450, 2010.

13 M. L. Rousset, Bull. Soc. Chim. Fr., 1897, 300.

14 W. Gu, A. J. Hill, X. Wang, C. Gui and R. G. Weiss, Macromolecules, 2000, 33, 7801.

15 A. Allen, P. Marquand, R. Burton, K. Villeneuve and W. Tam, J. Org. Chem., 2007, 72, 7849.

16 L. Antonov and D. Nedeltcheva, Anal. Lett., 1996, 29, 2055; L. Antonov and D. Nedeltcheva, Chem. Soc. Rev., 2000, 29, 217.

17 L. Antonov and V. Petrov, Anal. Bioanal. Chem., 2002, 374, 1312.

18 G. M. Sheldrick, Acta Crystallogr., Sect. A: Found. Crystallogr., 2008, 64, 112.

19 M. Frisch, G. Trucks, H. Schlegel, G. Scuseria, M. Robb, J. Cheeseman, G. Scalmani, V. Barone, B. Mennucci, G. Petersson, H. Nakatsuji, M. Caricato, X. Li, H. Hratchian, A. Izmaylov, J. Bloino, G. Zheng, J. Sonnenberg, M. Hada, M. Ehara, K. Toyota, R. Fukuda, J. Hasegawa, M. Ishida, T. Nakajima, Y. Honda, O. Kitao, H. Nakai, T. Vreven, J. Montgomery, Jr, J. Peralta, F. Ogliaro, M. Bearpark, J. Heyd, E. Brothers, K. Kudin, V. Staroverov, R. Kobayashi, J. Normand, K. Raghavachari, A. Rendell, J. Burant, S. Iyengar, J. Tomasi, M. Cossi, N. Rega, J. M. Millam, M. Klene, J. Knox, J. Cross, V. Bakken, C. Adamo, J. Jaramillo, R. Gomperts, R. Stratmann, O. Yazyev, A. Austin, R. Cammi, C. Pomelli, J. Ochterski, R. Martin, K. Morokuma, V. Zakrzewski, G. Voth, P. Salvador, J. Dannenberg, S. Dapprich, A. Daniels, O. Farkas, J. Foresman, J. Ortiz, J. Cioslowski and D. Fox, Gaussian 09, Revision A.02, Gaussian, Inc, Wallingford CT, 2009.

20 Y. Zhao and D. Truhlar, Theor. Chem. Acc., 2008, 120, 215; Y. Zhao and D. Truhlar, Acc. Chem. Res., 2008, 41, 157.

21 F. Weigend and R. Ahlrichs, Phys. Chem. Chem. Phys., 2005, 7, 3297 .

22 S. Kawauchi and L. Antonov, J. Phys. Org. Chem., 2013, 26, 643.
23 J. Tomasi, B. Mennucci and R. Cammi, Chem. Rev., 2005, 105, 2999.

24 S. B. Boys and F. Bernardi, Mol. Phys., 1970, 19, 553; S. Simon, M. Duran and J. Dannenberg, J. Chem. Phys., 1996, 105, 11024.

25 R. Improta, UV-Visible Absorption and Emission Energies in Condensed Phase by PCM/TD-DFT Methods, in Computational Strategies for Spectroscopy, ed. V. Barone, Wiley-VCH, Weinhein, 2012; D. Jacquemin, B. Mennucci and C. Adamo, Phys. Chem. Chem. Phys., 2011, 13, 16987.

26 S. Kawauchi, L. Antonov and Y. Okuno, Bulg. Chem. Commun., 2014, 46A, 228.

27 L. Antonov, V. Deneva, S. Simeonov, V. Kurteva, A. Crochet, K. M. Fromm, B. Shivachev, R. Nikolova, M. Savarese and C. Adamo, ChemPhysChem, 2015, 16, 649.

28 A. Koll and P. Wolschann, Monatsh. Chem., 1999, 130, 983. 29 E. Haslinger and P. Wolschann, Monatsh. Chem., 1980, 111, 563.

30 M. Rospenk, L. Sobczyk, P. Schah-Mohammedi, H.-H. Limbach, N. Golubev and S. Melikova, Magn. Reson. Chem., 2001, 39, S81. 31 P. M. Tolstoy, P. Schah-Mohameddi, S. N. Smirnov, N. S. Golubev, G. S. Denisov and H.-H. Limbach, J. Am. Chem. Soc., 2004, 126, 5621.

32 K. Schreiber and M. C. Kennedy Sr., J. Am. Chem. Soc., 1956, 78, 153; C. Creamer, A. Fisher, B. Mann, J. Packer, R. Richards and J. Vaughan, J. Org. Chem., 1961, 26, 3148.

33 R. Arnold and J. Sprung, J. Am. Chem. Soc., 1939, 61, 2475.

34 M. I. Kamlet, J. M. L. Abboud, M. H. Abraham and R. W. Taft, J. Org. Chem., 1983, 48, 2877; M. Abraham, P. Grellier, J. Abboud, R. Doherty and R. Taft, Can. J. Chem., 1988, 66, 2673.

35 N. Karger, M. da Costa and P. Ribeiro-Claro, J. Phys. Chem. A, 1999, 103, 8672; M. Marques, M. da Costa and P. Ribeiro-Claro, J. Phys. Chem. A, 2001, 105, 5292; P. Vaz, M. Nolasco, N. Fonseca, A. Amado, A. da Costa, V. Felix, M. Drew, B. Goodfellow and P. Ribeiro-Claro, Phys. Chem. Chem. Phys., 2005, 7, 3027.

36 M. Kasha, H. Rawls and M. El-Bayomi, Pure Appl. Chem., 1965, 11, 371.

37 L. Antonov, G. Gergov, V. Petrov, M. Kubista and J. Nygren, Talanta, 1999, 49, 99.

38 L. Sobczyk, Appl. Magn. Reson., 2000, 18, 47. 